\title{
A Health Production Function for Sub-Saharan Africa (SSA)
}

\author{
Bichaka Fayissa ${ }^{*}$ \\ Middle Tennessee State University, Murfreesboro, TN \\ Paulos Gutema** \\ Institute of Development Research \\ Addis Ababa University, Ethiopia
}

The paper estimates a health production function for Sub-Saharan Africa based on the Grossman (1972) theoretical model that treats social, economic, and environmental factors as inputs of the production system. In estimating this function, socioeconomic and environmental factors such as income per capita, illiteracy rate, food availability, ratio of health expenditure to GDP, urbanization rate, and carbon dioxide emission per worker are specified as determinants of health status, proxied by life expectancy at birth. The parameters of the function are estimated by a method of one-way and two-way panel data analyses. The results obtained from two-way random effect model suggest that an increase in income per capita, a decrease in illiteracy rate, an increase in food availability are well associated with improvement in life expectancy at birth. Overall results suggest that a health policy, which may focus on the provision of health, services, family planning programs, and emergency aids to the exclusion of other socioeconomic aspects may do little in efforts directed toward improving the current health status of the region.

Keywords: Sub-Saharan Africa, Health expenditure, Production function, Medical care, Panel data

JEL classification: I12; I18

* Bichaka Fayissa, Department of Economics and Finance, Middle Tennessee State University, Murfreesboro, Tennessee 37132, Tel. (615) 898-2385, Fax: (615) 898-5596, e-mail: bfayissa@mtsu.edu 


\section{A Health Production Function \\ for Sub-Saharan Africa (SSA)}

\section{Introduction:}

In attempts made to improve the human welfare, good health acts both as an important means and a basic end. As a result, economic development specialists and policy makers are seen paying due attention in seeking a viable and efficient mechanism for improving the health status of society. Over periods of time, such efforts have exhibited impressing results in many parts of the world.

Some African development specialists and policy makers have also been taking important steps in this regard. However, the health status of Sub-Saharan Africa (SSA) is still considerably low and exists below that of most parts of the world. Low life expectancy at birth, high infant and maternal mortality rates, and malaria and tuberculosis afflictions are some of the unique images of the health status of the African content. According to World Bank (2002) data set, in the 1990s, a new infant born in SSA has expected 42 life-years to live, but if the same infant were born in high-income countries of the world during the same period, it would have expected 70 years to live. Leaving aside the high-income groups, the infant would have expected 46 years had it been from other low-income countries. Not only is the level of expected life disappointing, but also its dynamics is equally alarming. In low and middle-income countries, the average life expectancy at birth has improved from the 1960s to the 1990s by about 13 and 15 life-years, respectively; in SSA, however, it has only changed by about 7 life-years during the same period. This change is also far below the world average of about 11 years. 
A similar phenomenon can also be observed from other indicators. In 1960s, the average number of infants dying before reaching one year of age per 1,000 live births was estimated to be 154, while it was only about 27 in high-income countries. From the 1960s to 1990s, the high income and middle income countries have reduced this figure by about 77 and 65 percent, respectively, while SSA has reduced infant mortality by only 38 percent which is also below the world's average of almost 50 percent. The intended progress might have been hampered by different socioeconomic, political, and environmental factors. Nonetheless, this study perceives that the health status of SSA can be substantially improved despite the prevailing distressing health conditions.

This paper estimates a health production function for the region based on the ground of Grossman (1972) theoretical model. The model treats social, economic, and environmental factors as inputs of the production system. The major advantages of estimating an aggregate health production function is that estimates of the over-all effect of medical care utilization on the health status of the population can be obtained (Thornton, 2002). This information can help policy makers and practitioners in their search for cost effective mechanisms for providing health services and the reallocation of health resources in such a way that the gains from health spending could be optimized.

The remaining sections of the paper are organized as follows. The next section outline an empirical framework derived from the Grossman (1972) theoretical model. Section three describes data and the econometric methods to be followed in the estimation process. The last two sections will present and interpret the results and draw some conclusions. 


\section{The Framework:}

Grossman (1972) developed a theoretical health production function, which can be specified as:

$$
H=F(X)
$$

Where $\mathbf{H}$ is a measure of individual health output and $\boldsymbol{X}$ is a vector of individual inputs to the health production function $\mathbf{F}$. The elements of the vector includes: nutrient intake, income, consumption of public goods, education, time devoted to health related procedures, initial individual endowments like genetic makeup, and community endowments such as the environment.

This theoretical model was designed for analysis of health production at micro level. The interest here is, however, to analyze the production system at macro level. To switch from micro to macro analysis, without losing the theoretical ground, the elements of the vector $\boldsymbol{X}$ were represented by per capita variables and regrouped into sub-sectoral vectors of economic, social, and environmental factors as:

$$
\mathbf{h}=\mathbf{F}(\mathbf{Y}, \mathrm{S}, \mathrm{V})
$$

Where $\boldsymbol{Y}$ is a vector of per capita economic variables, $\boldsymbol{S}$ is a vector of per capita social variables and $\boldsymbol{V}$ is a vector of per capita environmental factors. In its scalar form, equation (2) can be rewritten as

$$
h=f\left(y_{1}, y_{2}, \ldots y_{n}, s_{1}, s_{1}, \ldots s_{m}, v_{1}, v_{2}, \ldots v_{l}\right)
$$

Where $\boldsymbol{h}$ is individual's health status proxied by life expectancy at birth, $\left(\boldsymbol{y}_{1}, \boldsymbol{y}_{2}, \ldots \boldsymbol{y}_{\boldsymbol{n}}\right)=\boldsymbol{Y}$; $\left(s_{1}, \ldots s_{m}\right)=S ;\left(v_{1}, v_{2}, \ldots v_{l}\right)=V$, and $n, m$, and 1 are number of variables in each sub-group, respectively.

Using calculus, (3) can be transformed to its explicit form and given as

$$
h=\Omega \Pi y_{i}^{\alpha I} \Pi s_{j}^{\beta j} \Pi y_{i}{ }^{k k}
$$


where $\alpha_{i}, \beta_{j}, \gamma_{k}$ are elasticities.

From (4), we observe that $\boldsymbol{\Omega}$ estimates the initial health stock pointed out by Grossman (1972). It measures the health status that would have been observed had there were no health depreciation, or health improvement due to changes in socioeconomic and environmental factors used in the production system. Similarly, $\left(\Pi y_{i}^{\alpha i} \Pi s_{j}^{\beta j} \Pi y_{i}{ }^{2 k}-1\right) x \mathbf{1 0 0 \%}$ will estimate the percentage change in the health status due to socioeconomic and environmental factors.

In the empirical analysis, the list of the variables in each sub-group may not necessarily be uniform across different regions of the study. This is because the factors may partly be influenced by the existing cultural and environmental conditions of a country under study. Behrman and Deolalikar (1988) warn that care must be taken in empirical analysis to consider an appropriate range of the inputs and not just those that are identified with public health measure or curative medicine in advanced countries. Moreover, the availability of continuous, reliable and sufficient data on the variables in the list is another limiting factor.

Consequently, for our empirical analysis here, the variables representing economic factors are limited to includes GDP per capita $\left(\boldsymbol{y}_{1}\right)$, health expenditure per capita $\left(\boldsymbol{y}_{2}\right)$ and food availability $\left(\boldsymbol{y}_{3}\right)$; variables representing social factors are limited to education $\left(\boldsymbol{s}_{\mathbf{1}}\right)$, life style which is represented by adult alcohol consumption per capita $\left(\boldsymbol{s}_{2}\right)$, and population $\left(\boldsymbol{s}_{3}\right)$; and variables representing environmental factors include urbanization $\left(\boldsymbol{v}_{1}\right)$ and carbon dioxide emissions per capita $\left(\boldsymbol{v}_{2}\right)$. The population variable enters the equation to augment food availability data, as the data exists at aggregate index form. Taking the logarithm of (4) and rearranging it yields:

\section{$\operatorname{Lnh}=\ln \Omega+\Sigma \alpha_{i}\left(\ln y_{i}\right)+\Sigma \beta_{j}\left(\operatorname{lns}_{j}\right)+\Sigma \gamma_{k}\left(\ln v_{k}\right), \ldots \ldots \ldots \ldots \ldots \ldots \ldots \ldots \ldots$ (5)}


Where $\boldsymbol{i}=1,2,3 ; \boldsymbol{j}=1,2,3$; and $\mathbf{k}=\mathbf{1}, \mathbf{2}$ and $\Omega$ is an estimate of the initial health stock of the region.

In the following sections, we construct an empirical model to obtain econometric estimates of the parameters given in (5). The results will help us to determine the relative importance and significance of the factors used in health production function of the region.

\section{Data and Methods}

\section{A. Variables and the Data}

Estimation of health production function given by equation (5) requires data on health status as well as on socioeconomic and environmental variables. However, measuring health status directly is somewhat difficult and, for aggregate studies, some researchers ${ }^{1}$ suggest life expectancy, particularly at birth and mortality rate, particularly for infants and children, as indicators of the health output. In our study, we employ life expectancy at birth as the dependant variable. It indicates the number of years a newborn infant would live if prevailing patterns of mortality at the time of its birth were to stay the same throughout its life. The explanatory variables and their expected coefficients are described below.

From the right hand side of the function, as indicated in equation (5), GDP per capita, health expenditure per capita, food availability, illiteracy rate, population, adult alcohol consumption per capita, urbanization rate, and $\mathrm{CO}_{2}$ emissions are used.

\footnotetext{
${ }^{1}$ See, for example, Beherman and Deolalikar (1988: 698-701)
} 
GDP per capita which is calculated in constant U.S. dollars is expected to have a positive coefficient i.e. a higher level of income permits more access to consumption of higher quality of goods and services, better housing, and medical care services which favorably influence the health status. Moreover, as income increases, there is a general tendency to move away from jobs with higher stress which may adversely affect health status. However, some researchers argue that beyond some threshold level of affluence, increasing income may no longer buy better health. In fact, it may lead to a stressful and unhealthy life style that may adversely affect health status. More explicitly, as income increases individuals may choose more adverse diets, faster cars, lesser exercises etc. (for such arguments, see for example, Fuchs, 1994; Auster, Levenson, and Sarachek, 1969; Rodger, 1979; Wilkinson, 1992; and Christiansen 1994). Based on the later scenario, the coefficient of income per capita is expected to be negative. Since income per capita is generally low in SSA, the latter view is very unlikely to hold, and hence, we expect the sign of the coefficient to be positive.

The second representative of an economic factor is health expenditure. It constitutes both public and private health expenditure and covers the provision of health services, family planning activities, and emergency aid designed for health. Generally, it is considered as a measure of availability of the health production facilities to a given society. Indeed, some empirical studies use stock of facilities like hospital beds per 1000 people, physician per 1000 people etc. instead of expenditure on health. However, Hadley (1982) states that using medical care expenditures as a measure of the provision of the facilities is more desirable than using a stock of providers because variation in expenditures across geographic areas better reflects the differences in quality and quantity of such services. 
On the other hand, the use of health expenditures per capita as the measure of provision of the facilities entails another econometric problem of multicollinierty that arises from co-movement of health expenditures and income. To reduce the possible effects of multicollinierty, we used the ratio $^{2}$ of total health expenditure to GDP as indicator of availability of the facilities per capita. The expected relationship between health expenditure and life expectancy is, however, somewhat ambiguous. On the one hand, higher levels of per capita health expenditures may help to increase the provision of health facilities, which in may turn help, improve life expectancy. However, this is only true if the increment in expenditure has no adverse effect on the individual's health status. An adverse effect may arise if the expenditures are financed by revenues collected from user fees, or taxes, and if the fees and tax payments are made at the expense of the individual preventive health cares such as food, clothing, and housing as which may occur subsistence societies. In this situation, unless the marginal effect of an increase in the facility is so high to compensate the forgone benefits from preventive health care, it is normal to obtain a negative coefficient ${ }^{3}$ for the variable. Therefore, the sign of the coefficient cannot be predicted a priori.

The third representative of economic factor is food availability. Given that the problem of nutrition in poor economies is more of scarcity and not of over consumption, we expect positive coefficient for food availability. Food production index was used as a measure of food availability. It covers food crops that are considered edible and that contain nutrients. Coffee and

\footnotetext{
$2 \mathrm{~d}(\ln \mathrm{X} / \mathrm{P})=\mathrm{d}(\ln \mathrm{X}-\ln \mathrm{P})=\mathrm{d}(\ln \mathrm{X})-\mathrm{d}(\ln \mathrm{P})$, but growth of aggregate income could be approximated by population growth due to stagnant nature of the economic performance, hence $\mathrm{d}(\ln \mathrm{P}) \approx \mathrm{d}(\ln \mathrm{Y}) \Rightarrow \mathrm{d}(\ln \mathrm{X} / \mathrm{P}) \approx \mathrm{d}(\ln \mathrm{X})$ - $\mathrm{d}(\ln \mathrm{Y})=$ $\mathrm{d}(\ln \mathrm{X} / \mathrm{Y})$. i.e. the ratio substitutes the per capita expenditure in equation (6)

${ }^{3}$ For a mathematical analysis of the possibility of the negative coefficient see, Appendix: 1
} 
tea are excluded because, although edible, they have no nutritive value. The index requires inserting population in the function as a correction of aggregate figures to per capita levels.

Social factors were represented by variables of education, adult alcohol consumption per capita, and population. In deed, in using education as a social factor, we recognize the argument of some writers that states education is not an input by itself, as Wolfe and Behrman (1984) have argued; it is introduced in the function to increase the marginal efficiency of other inputs. Adult illiteracy rate is taken as a proxy for education. It is the percentage of people above 15 years who cannot read, write, and understand a simple statement on their daily activities. Grossman (1972) and other studies have argued that education influences many decisions (such as a choice of job, ability to select a healthy diet, and avoid unhealthy habits, efficient use of medical care) which impacts the quality of life. Berger and Leigh (1989), Rosen and Taubau (1982: 255-71) and others have provided empirical evidence in support of this argument. We, therefore, hypothesize that the more literate society is the healthier its people will be, and hence we expect a negative coefficient of adult illiteracy rate.

The second social factor is life style; it represented by adult alcohol consumption per capita. It is measured by the amount of pure ethanol in liters of total alcohol consumed per adult (15 years and older) in the country during a calendar year, as calculated from official statistics on production, sales, imports, and exports, taking into account stocks whenever possible. The source of the data is World Health Organization's (WHO) alcohol consumption database. According to Chick et al. (1986), and Choquent and Ledoux (1989), alcohol consumption is recognized as an important risk factor for most chronic illnesses such as diseases of the digestive system, cancer, 
cirrhosis etc. as well as for accidents and violent deaths. Thus we expect a negative coefficient for this variable.

Population is another variable used as a demographic social factor. Even though it is unconventional to use it as health production input, here it appears in the function in relation with food availability. The food production index employed in the economic factors, exists in aggregate form rather than appearing in per capita form, But what is needed is per capita availability of food. We introduce the population variable in the function to correct the food availability index. Keeping all else constant, the larger population size, the lesser the food availability; hence, we expect a negative coefficient for the population variable.

Lastly, we consider urbanization rate or the share of the total population living in areas defined as urban in each country and carbon dioxide emissions per capita to capture the effect of environmental factors on life expectancy. Thornton (2002) states that urbanization is a proxy for a collection of potential negative and positive health related factors. On the positive side, he notes that it avails access to medical care and health information. In a slightly different context, Rosenzweig and Shultz (1982, pp. 58-59) argue that urban public health institutes are substitutes for health care knowledge and management capacity that an educated individual brings to his family. Moreover, it is argued that in urban areas clinics are more cost-effective. On the negative side, Thornton (2002) indicates that urbanization is associated with pollution and congestion that has an adverse effect on health. Holding the two sides together, it is not so difficult to think that the marginal effect of urbanization depends on the net effect of the two contradictory factors. Hence, the sign of urbanization cannot be predetermined. 
Carbon dioxide emissions per capita is another variable we considered as environmental factor. Emissions from the burning of fossil fuels and the manufacture of cement are used as a proxy for the environmental factors. They include contributions to the carbon dioxide produced during consumption of solid, liquid, and gas fuels and gas flaring. Since the emissions cause air pollution that in turn causes health hazards, we expect negative coefficient for the variable. Lastly, it is worth mentioning that all of the above listed data set was taken from World Bank (2002), unless otherwise stated. Data incompleteness dictated the study to be confined to a period of 1990-2000, and to $33^{* * i}$ Sub-Sahara African countries.

\section{B. Estimation Method}

For estimation of the parameters under consideration, a panel data analytic approach is employed. In forming the panel, the time series data of each country was averaged over two years and a total of five periods were formed for each country, then an econometric model is specified for (5) in its general form. In order to provide an empirical exposition of the model the specification is given as follows:

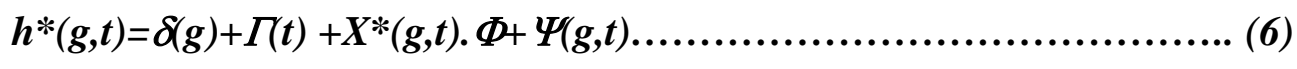

Where $\mathrm{h}^{*}(\mathrm{~g}, \mathrm{t})$ is natural logarithm of life expectancy in country $g$ at year $t$, and $\boldsymbol{X}^{*}(\boldsymbol{g}, \boldsymbol{t})$ is vector of explanatory variables $\left(y_{1}, y_{2}, y_{3}, S_{1}, S_{2}, S_{3}, v_{1}, v_{2}\right)$ for $g=1,2, \ldots m$ (number of countries), $t=1,2, \ldots T$ (number of years), $\boldsymbol{\Phi}$ is vertical vector of parameters $\left(\alpha_{1}, \alpha_{2}, \alpha_{3}, \beta_{1}, \beta_{2}, \beta_{3}, \gamma_{1}, \gamma_{2}\right) ; \Psi(g, t)$ is a classical stochastic disturbance term with $E[\Psi(g, t)]=0$ and $\operatorname{var}[\Psi(g, t)]=\sigma_{\varepsilon}^{2} ; \delta(g)$ and $\Gamma(t)$ are group and time specific effects, respectively. Instead of a priori decision on the behavior of $\delta(g)$

and $\Gamma(t)$, five different types of the most common assumptions are separately imposed on the model and the one that gives superior estimate is selected based on statistical rules. 
The first assumption is that all of the country specific effects are constant and equal across the countries; and the time specific effects are not present, i.e. $\delta(g)=\lambda$ and $\Gamma(t)=0$, for some constant $\lambda$. Under this assumption, model (6) is estimated by ordinary least squares (OLS) method and the results are reported as Restricted OLS Model.

The second and third alternative specifications assume absence of time specific effects, which is basic attribute of One-Way specification. The second estimation technique assumes that country specific effects are constant like the first one, but not necessarily equal, i.e. $\delta(g)=\lambda(g)$ and $\Gamma(t)$ $=0$, for some constants $\lambda(g)$. Under this case, equation (6) is estimated by a partitioned OLS. The estimates are reported under One-Way Fixed Effects Model.

The third assumption type tested in the analysis is that individual specific effects are not constants, but rather are disturbances; and the time specific effects are not present here again i.e. $\delta(g)=\lambda+w(g)$ and $\Gamma(t)=0$, where $E\left[(w(g)]=0\right.$, and $\operatorname{var}[w(g)]=\sigma^{2} w$ and $\operatorname{cov}[\Psi(g, t), w(g)]=0$. Unlike the previous cases, here equation (6) is estimated by a feasible, 2-step, Generalized Least Squares (GLS). The results of this estimation are given under the One Way Random Effects Model.

The fourth and the fifth assumptions, basic feature of Two-Way specification, differ from the first three in their time specific effects components. The fourth assumption requires that both group and time specific effects are constants, but are not necessarily equal; and there is an overall constant, i.e. $\delta(g)+\Gamma(t)=\lambda^{\prime}+\lambda^{\prime}(g)+\gamma(t)$, where $\lambda^{\prime}, \lambda^{\prime}(g)$ and $\gamma(t)$ are some constants. The results of this estimation are reported under the Two-Way Fixed Effects Model. 
The last assumption is that both the country specific and time specific effects are disturbances

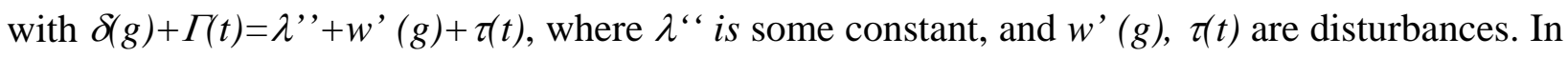
this case, just as in assumption three above, equation (6) is estimated by 2-step GLS model. The results of the estimation were reported under Two Way Random Effects Model.

After estimating the parameters on the ground of these five assumptions, the superior specification is selected on the ground of suitable statistical test.

\section{Econometric Results}

Equation (--) is estimated using the data and method described above. The empirical results are given in tables 1 and 2. To choose from One-Way and Two-Way specifications, we use the Fstatistics. The statistics tests the significance of any time specific effects that is not included in One-Way regression specification. The test result given at the bottom of table 2, suggests that Two-Way error component regression model is superior to One-Way, $(\boldsymbol{p}=\mathbf{0 . 0 0 1 6})$.

\section{Table-1}

\section{Table-2}

The next step will be selecting appropriate estimator from the three given estimators. To start with, the poolability or appropriateness of the constrained model, or OLS estimator is tested. In other words, this test helps us to examine the hypothesis of absence of country specific effects. With $\mathrm{N}=33 \mathrm{~T}=5$ and $\mathrm{k}=7$, a Lagrange-multiplier test for significance of country specific effects yields a $\chi^{2}$-value of $155.86, \boldsymbol{p}=\mathbf{0 . 0 0 0 0}$. This is distributed as $\chi_{(2)}^{2}$ under the null hypothesis of zero country specific effects. The null is soundly rejected, and the within or the random effect model is preferred to OLS estimator. That is, the test does not support the poolability of the data set, suggesting that there are strong country-specific effects. 
Next, for the choice between random effects (GLS estimator) and within effect estimator a Hausman-test is performed. The basic assumption associated with random effect is that there is no correlation between the regressor and country specific effects. If such assumption is violated, then the GLS estimator will be biased and inconsistent. The test shows a $\chi^{2}$ value equal to 3.88 , $\left(\boldsymbol{p}=\mathbf{0 . 6 9 3 5 )}\right.$. This is distributed as $\chi_{(6)}^{2}$ under the null hypothesis of absence of the indicated correlation. The null hypothesis of no correlation between the country specific effect and the regressor is strongly accepted. This implies that the GLS estimator in this case is unbiased and consistent. As a result, the preferable estimates of the parameters in equation (--) can be given by two-way random effect models.

The coefficient of food availability measured in per capita terms is found to be positive and statistically significant, suggesting that the variable favorably influence health status of the region in the periods of good economic growth performance. The results suggest that a one per cent increment food availability per capita can generate about 0.13 percentage improvement in health status. The estimate further suggest that if the region's economies are able to repeat their food production performance during the second half of 1980 s (about $0.53 \%$ growth on food production per capita), then it is possible to improve life expectancy by about 2.5 life-years, other things remaining unchanged. In short, the parameter estimate of this variable suggests that successful policies that aim at increasing food availability of the region can have an impressive impact on the health status of the region.

On the other hand, the table reports a negative and statistically significant coefficient of health expenditure. The negative sign might have arisen from the actual nature of the relationship 
existing between health expenditures per capita and life expectancy. This could happen if the society is close to subsistence, i.e. has meager, or no savings, and if the expenditures are financed through user fees or taxes collected from the users. In this case, an increase in the expenditures will have a consumption reducing effect of life nurturing and sustaining goods such as food, clothing, housing etc, as it competes for the budget allocated for such types of goods. If the marginal effect of the latter types of goods exceeds that of the former types, the health facilities to be provided by increased expenditures, then it is not surprising to get a negative coefficient for the health expenditures variable.

The analytical result given in appendix-1 suggests that the negative coefficient is due to cost ineffective provision of health facilities, when seen from its opportunity cost perspective. Putting it in other words, the facilities could not restore the forgone health benefits that arise in the process of obtaining them. Thus, we feel that reversing the existing trend is one of the areas that deserve special attention in efforts directed to the improvement of the health status of the region.

Moreover, the table reports that the coefficient of the illiteracy ratio has a statistically strong impact on health status, $(\mathbf{P}=\mathbf{0 . 0 0 0 0 )}$, suggesting that a one percent reduction in the illiteracy ratio (which is an approximation of the 1990s educational performance of 1.17 percent) would lead to $0.004 \%$ increment in life expectancy. As previously discussed, this is possible as more education gives the people more awareness about their own health status and of what preventive measures would increase their own health.

Furthermore, the table indicates that alcohol consumption has got strong negative impact on health status. The variable has got statistically significant $(p=0.0308)$, negative coefficient. 
Lastly, the table indicates that an increase in urbanization rate and a decrease in carbon dioxide emission may contribute to the improvement of health status. This suggestion is, however, not supported by statistical test of significance.

\section{Summary and Conclusion:}

The study has tried to investigate the determinants of health status in Sub-Sahara Africa in line with Grossman theoretical model using socioeconomic and environmental factors as inputs of the production system. The main source data source for study is the World Bank (2002) data set, with the exception of the alcohol consumption data which were drawn from WHO's database. To overcome data limitation, we used pooled cross-section time series 33 SSA countries covering 1990-2000 period.

The results obtained from two-way random effect regression model suggest that an increase in food availability per capita, literacy rate and a decrease in alcohol consumption have a significant favorable effect on life expectancy. Health expenditure has shown strong negative relationship with life expectancy, which possibly arises from inefficient health service provision systems. Moreover, an increase in urbanization and a decrease in Carbon dioxide emissions per capita growth rate are found to improve life expectancy, though this argument cannot be supported based on the statistical significance of the tests.

In general, the results suggest that health policy which may focus on provision of health services, family planning programs, and emergency aids and ignores marginal efficiencies of the services, and other socio-economic aspects may do little in efforts directed to improve the existing health status of the region. Lastly, from the analysis and the region's past socioeconomic performances, 
we observe the fact that making substantial improvements of the health status of SSA are within the realm of possibility. 


\section{Appendix-1: Coefficient for Health Expenditure}

Consider some consumption goods or services, $\boldsymbol{n}$, other than health facilities, say food or clothing or housing. Suppose that consumption of goods $\boldsymbol{n}$ contribute to health improvement and the resource required for its provision competes for the same budget with health facility provision. In the cases where government provides the facilities, we think of the part of tax paid by the individual that aims at covering the cost of the provision. Obviously, consumption per capita of $\boldsymbol{n}$ will be a function of income per capita, $\left(\mathbf{y}_{1}\right)$, health expenditure per capita $\left(\boldsymbol{y}_{2}\right)$ and the purchase of other goods not related to health (I). The implicit function of $\boldsymbol{n}$ will take the form of

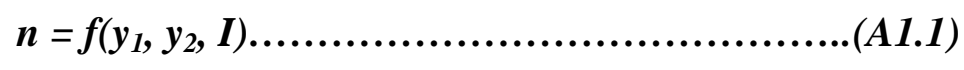

Solving for the explicit form of (A1.1), we get

$$
n=\alpha_{0} y_{1}^{\alpha 1} y_{2}^{\alpha 2} I^{\alpha 3}
$$

where ${ }_{1}^{\alpha}, \alpha_{2}$, and ${ }_{3}^{\alpha}$ are elaticities.

In subsistence economies, where increment in $\mathbf{y}_{\mathbf{2}}$ is made possible only at the expense of $\boldsymbol{n}$, i.e. where $\boldsymbol{I}=\mathbf{0}$, we expect $\boldsymbol{\alpha}_{2}<0$. Since we are assuming that $\boldsymbol{n}$ is one of the inputs of health production system, our function includes $\boldsymbol{n}$ as one of its inputs. That is

$$
h=f\left(n, y_{1}, y_{2}, z\right)
$$

where $\mathbf{z}$ represents all other inputs not related to income.

The explicit function of [A1.3] will be

$$
h=\beta_{0} n^{\beta 1} y_{1}^{\beta 2} y_{2}^{\beta 3} Z^{\beta 4}
$$

where $\boldsymbol{\beta}_{1}, \boldsymbol{\beta}_{2}, \boldsymbol{\beta}_{3}$ and $\boldsymbol{\beta}_{4}$ are elaticities. Substituting (A1.2)in (A1.4)we get

$$
h=\beta_{0} \alpha_{0}^{\beta 1} y_{1}^{\alpha 1 \beta 1+\beta 2} y_{2}^{\alpha 2 \beta 1+\beta 3} I^{\alpha 3 \beta 1} Z^{\beta 4}
$$

From (A1.5), we observe that there are circumstances in which $\boldsymbol{\alpha}_{2} \boldsymbol{\beta}_{1}+\boldsymbol{\beta}_{2}$, i.e. the coefficient of health expenditure, becomes negative. That is, if $\boldsymbol{\beta}_{2}$ (marginal effect of health expenditure through health facility provision) is small, if marginal effect of $\boldsymbol{y}_{2}$ on $\boldsymbol{n}\left(\boldsymbol{\alpha}_{2}\right)$ is high, and if marginal contribution of consumption of goods $\boldsymbol{n}$ to health improvement $\left(\alpha_{1}\right)$ is high in such away that $\left|\alpha_{2} \beta_{1}\right|>\beta_{2}$, then we have $\alpha_{2} \boldsymbol{\beta}_{1}+\boldsymbol{\beta}_{2}<\mathbf{0}$ since $\boldsymbol{\alpha}_{2} \boldsymbol{\beta}_{1}<\mathbf{0}$. In short, gains from marginal increment of health expenditure become negative. 


\section{References}

Auster, R., Levenson, I. And Sarachek, D. (1969), “The Production of Health, an Exploratory Study”, Journal of Human Resources, 4: 411-36.

Berger, M. and Leigh, J. (1989), "Schooling, Self-selection, and health”, Journal of Human Resources, 24: 433-55.

Behrman, Jere R. and Anil B. Deolalikar (1988), "Health and Nutrition,” in Hollis Chenery and T. N. Srinivasan, eds., Hand-book of Development Economics, Volume I: 1988, Amsterdam: NorthHolland.

Chick J., J. Duffy, G. Lloyd, B. Ritson (1986), “Medical Admissions in Men: The Risk Among Drinkers”, The Lancet, ii: 1380-83.

Chistiansen, T. (1994), "Distribution of Health Status by Income. Result from Denmark,” in A. Mielck and R. Maria, eds., Health inequalities: Discussion in Western European countries, Waxmann, Munster/New York.

Choquet, M. and S. Ledoux (1989), “Alcohol Related Problems in France” in WHO EURO Reports and Studies, 109: 45-63.

Fuchs, V., (1994), The Future of Health Policy, Harvard University Press: Cambridge.

Grossman, M. (1972), The Demand for Health: A theoretical and Empirical Investigation, NBER: New York.

Hadley, J. (1982), More Medical Care, Better Health, Urban Institute: Washington DC.

Rogers, G.B. (1979), "Income and Inequality as Determinants of Mortality: An International Cross section analysis”, Population Studies, 33(2): 343-52.

Rosen S. and Taubman, P. (1982), "Some Socioecono0mic Determinants of Mortality," in J. Van der Gagg, W.B Neeman and T. Tsukahara, eds., Economics of Health Care: 1982, New York, Preager Publishers.

Thornton, J. (2002), "Estimating a Health Production Function for the US: Some new Evidence”, Applied Economics, 34: 59-62.

Wilkinson, R. G. (1992), “Income Distribution and Life Expectancy”, British Medical Journal, 304:16568. 
Table 1: One-Way Error Component Regression Model Estimates for Equation (--)

\begin{tabular}{|c|c|c|c|c|c|}
\hline Estimators & Parameters & $\begin{array}{c}\text { Estimate of } \\
\text { the } \\
\text { parameter }\end{array}$ & $\begin{array}{c}\text { St. error of } \\
\text { the parameter }\end{array}$ & T-ratio & p-value \\
\hline \multirow{7}{*}{$\begin{array}{l}\text { Restricted } \\
\text { Model } \\
\text { OLS }\end{array}$} & $\alpha_{1}$ & -0.0206 & 0.0064 & -3.2135 & 0.0016 \\
\hline & $\alpha_{2}$ & 0.2122 & 0.0682 & 3.1115 & 0.0022 \\
\hline & $\beta_{1}$ & -0.0032 & 0.0006 & -5.4849 & 0.0000 \\
\hline & $\beta_{2}$ & -0.0160 & 0.0071 & -2.2335 & 0.0269 \\
\hline & $\gamma_{1}$ & 0.0029 & 0.0010 & 2.9619 & 0.0035 \\
\hline & $y_{2}$ & 0.0122 & 0.0081 & 1.5163 & 0.1315 \\
\hline & Constant & 3.1046 & 0.3125 & 9.9342 & 0.0000 \\
\hline \multirow{6}{*}{$\begin{array}{l}\text { Fixed } \\
\text { Effect } \\
\text { Model }\end{array}$} & $\alpha_{1}$ & -0.0350 & 0.0092 & -3.8227 & 0.0002 \\
\hline & $\alpha_{2}$ & 0.1511 & 0.0675 & 2.2376 & 0.0266 \\
\hline & $\beta_{1}$ & 0.0019 & 0.0021 & 0.9025 & 0.3682 \\
\hline & $\beta_{2}$ & -0.0331 & 0.0221 & -1.4960 & 0.1366 \\
\hline & $\gamma_{1}$ & -0.0036 & 0.0032 & -1.1300 & 0.2602 \\
\hline & $y_{2}$ & 0.0164 & 0.0204 & 0.8081 & 0.4203 \\
\hline \multirow{7}{*}{$\begin{array}{l}\text { Random } \\
\text { Effect } \\
\text { Model }\end{array}$} & $\alpha_{1}$ & -0.0337 & 0.0069 & -4.8924 & 0.0000 \\
\hline & $\alpha_{2}$ & 0.1645 & 0.0486 & 3.3841 & 0.0007 \\
\hline & $\beta_{1}$ & -0.0018 & 0.0010 & -1.8298 & 0.0673 \\
\hline & $\beta_{2}$ & -0.0165 & 0.0118 & -1.3919 & 0.1639 \\
\hline & $\gamma_{1}$ & -0.0018 & 0.0015 & -1.1976 & 0.2311 \\
\hline & $y_{2}$ & 0.0448 & 0.0125 & 3.5923 & 0.0003 \\
\hline & Constant & 3.5110 & 0.2322 & 15.1220 & 0.0000 \\
\hline
\end{tabular}

Lagrange Multiplier test of RM vs. FE/RE $\chi_{(1)}^{2}=139.24, p=0.0000$

Hausman test of FE vs. RE; $\chi_{(6)}^{2}=0.00, p=1.0000$

Table 2: Two-Way Error Component Regression

Model Estimates for Equation (--)

\begin{tabular}{lrrrrr}
\hline \hline Estimators & Parameters & $\begin{array}{c}\text { Estimate of the } \\
\text { parameter }\end{array}$ & $\begin{array}{c}\text { St. error of the } \\
\text { parameter }\end{array}$ & T-ratio & $\begin{array}{c}\text { p- } \\
\text { value }\end{array}$ \\
\hline Fixed Effect & $\alpha_{1}$ & -0.0343 & 0.0079 & -4.3539 & 0.0000 \\
\cline { 2 - 6 } & $\alpha_{2}$ & 0.1147 & 0.0515 & 2.2283 & 0.0273 \\
\cline { 2 - 6 } & $\beta_{1}$ & -0.0105 & 0.0042 & -2.4819 & 0.0141 \\
\cline { 2 - 6 } & $\beta_{2}$ & -0.0294 & 0.0218 & -1.3460 & 0.1802 \\
\cline { 2 - 6 } & $\gamma_{1}$ & 0.0016 & 0.0034 & 0.4735 & 0.6365 \\
\cline { 2 - 6 } & $\gamma_{2}$ & 0.0120 & 0.0259 & 0.4624 & 0.6444 \\
\hline Random & Constant & -0.9852 & 0.3464 & 11.5032 & 0.0000 \\
Model & $\alpha_{1}$ & -0.0302 & 0.0067 & -4.5223 & 0.0000 \\
\cline { 2 - 6 } & $\alpha_{2}$ & 0.1337 & 0.0474 & 2.8211 & 0.0048 \\
\cline { 2 - 6 } & $\beta_{1}$ & -0.0042 & 0.0010 & -4.1052 & 0.0000 \\
\hline \hline & $\beta_{2}$ & -0.0255 & 0.0118 & -2.1603 & 0.0308 \\
\hline & $\gamma_{1}$ & 0.0026 & 0.0016 & 1.6058 & 0.1083 \\
\hline
\end{tabular}




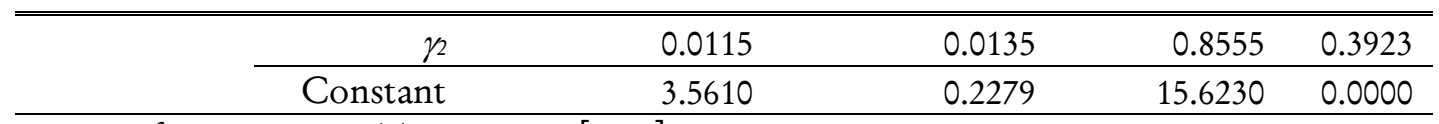

F-test of One-Way vs Two-Way $F[\mathbf{4}, \mathbf{2 2}]=4.633, \quad p=0 . \mathbf{0 0 3}$

Lagrange Multiplier test of $\mathrm{RM}$ vs. FE/RE $\chi_{(2)}^{2}=155.86, p=0.0000$

Hausman test of FE vs. RE; $\chi_{(6)}^{2}=3.88, p=0.0285$

** Benin, Botswana, Burkina Faso, Burundi, Cameroon, Cape Verde, Central African Republic, Chad, Cote d'Ivoire, Equatorial Guinea, Ethiopia, Gambia, Ghana, Kenya, Madagascar, Malawi Mali, Mauritania, Mauritius, Mozambique, Namibia, Niger, Nigeria, Rwanda, Senegal, South Africa, Sudan, Swaziland, Tanzania, Togo, Uganda, Zambia and Zimbabwe 